\title{
Mucocele apendicular en un paciente del Hospital General Zona № 1 del IMSS
}

\section{Reporte de un caso}

Prado-González Luis Gerardo*, González-García Marcela* ,Cruz-Valencia José Luis**, Rosas-Cabral Alejandro***

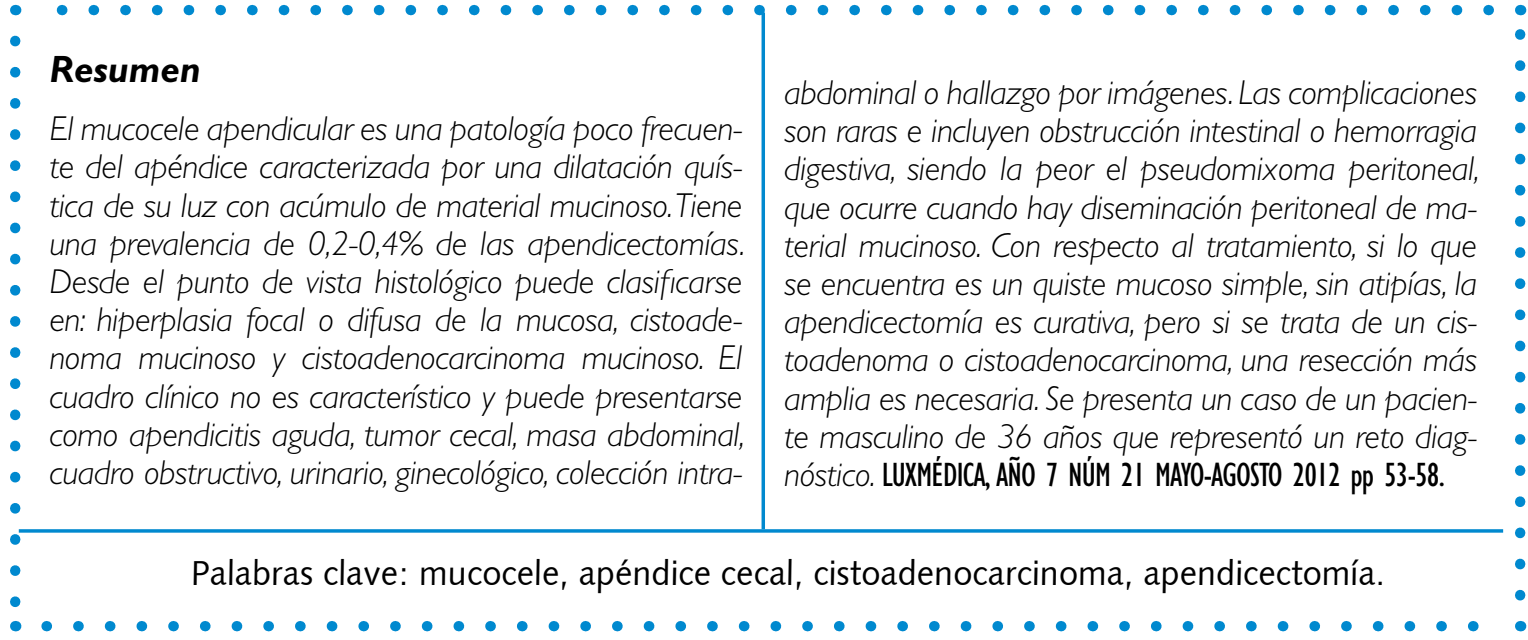

\section{Introducción}

El mucocele apendicular, inicialmente descrito por Rokitansky en 18421, es una patología poco frecuente del apéndice caracterizada por una dilatación quística de su luz, con acúmulo de material mucinoso. Por lo general es un hallazgo casual en el curso de la cirugía

* Médico Interno de Pregrado del Hospital General de Zona Número 1 del Instituto Mexicano del Seguro Social.

** Médicos adscritos al servicio de Cirugía del HGZ No 1 IMSS

*** Profesor investigador del Departamento de Medicina del Centro de Ciencias de la Salud de la Universidad Autónoma de Aguascalientes.

Fecha de recibido: 20 octubre 2011

Fecha de aceptación: 29 de junio 2012

Correspondencia: Dr Alejandro Rosas Cabral Departamento de Medicina del Centro de Ciencias de la Salud. Universidad Autónoma de Aguascalientes. Avenida Universidad 940 Ciudad Universitaria CP 20131. Aguascalientes, Ags, México. Teléfono 01449 9108536 Correo electrónico roal3micasa@aol.com 
abdominal realizada por otras razones y se certifica mediante el estudio histopatológico. Tiene una prevalencia de $0,2-0,4 \%$ de las apendicectomías $^{2}$. La proporción de mujer a hombre es de 4:1. La edad de presentación es por arriba de los 55 años. ${ }^{3}$ Desde el punto de vista histopatológico, el mucocele apendicular puede clasificarse en hiperplasia focal o difusa de la mucosa, cistoadenoma mucinoso y cistoadenocarcinoma mucinoso ${ }^{4}$, siendo el cistoadenoma mucinoso el más frecuente $(50 \%)$. Se ha descrito la presencia de otros tumores asociados, principalmente a nivel del tubo digestivo, llegando a asociarse en un $20 \%$ a neoplasias colorrectales, pero también en ovario (4-24\%), mama e hígado. A pesar de que se encuentran otras neoplasias gastrointestinales con una frecuencia seis veces superior a lo esperado, no está claro si la presencia de un mucocele apendicular representa un incremento del riesgo para padecer un cáncer colorrectal ${ }^{5}$. En México en una revisión exhaustiva en el servicio de Cirugía Gastrointestinal del Centro Médico Nacional Siglo XXI, del Instituto Mexicano del Seguro Social (IMSS), se encontraron 8950 casos de apendicetomía (incidencia del 1\%), en su gran mayoría de naturaleza benigna. ${ }^{6}$ El mucocele apendicular no tiene un cuadro clínico característico. ${ }^{7}$ La presentación clínica del mucocele es generalmente inespecífica o asintomática, ${ }^{1,8}$ y el estudio por imágenes permite sospechar el diagnóstico en el preoperatorio mostrando una masa quística en fosa iliaca derecha ${ }^{7}$. Hasta en un $50 \%$ resulta ser un hallazgo de la cirugía o de estudios de imágenes solicitados por otra patología. ${ }^{1,8}$

Entre los síntomas relacionados al mucocele están dolor abdominal, dolor cólico crónico o intermitente secundario a intususcepción del mucocele, masa en la fosa ilíaca derecha, sepsis o síntomas urinarios. ${ }^{1,8} \mathrm{El}$ diagnóstico se puede realizar eventualmente con radiografía simple de abdomen o colon por enema. Con el advenimiento del ultrasonido y la tomografía el diagnóstico se realiza con mayor certeza. ${ }^{9}$ Con respecto al tratamiento, si lo que se encuentra es un quiste mucoso simple, sin atipia, la apendicectomía es curativa, pero si se trata de un cistoadenoma o cistoadenocarcinoma, una resección con bordes quirúrgicos libres es necesaria. ${ }^{10}$ Si se demuestra malignidad deberá realizarse hemicolectomía ${ }^{6}$. El objetivo de este trabajo es reportar un caso de esta patología, poco frecuente y comentar sus características particulares.

\section{Presentación del caso}

Se trata de paciente masculino de 36 años de edad originario y residente de Aguascalientes, Ags. Tiene los siguientes antecedentes de importancia: Antecedentes heredo-familiares: diabetes mellitus (DM) en familiares directos, Antecedentes perso- 
nales patológicos: niega enfermedades crónico degenerativas, cirugías, fracturas, hospitalizaciones, transfusionales, alergias, tabaquismo abandonado hace 10años, alcoholismo social sin llegar a la embriaguez.

Inicia su padecimiento actual con sintomatología desde hace tres días con dolor y ardor en epigastrio, el cual se irradió a hipogastrio, acompañado de vómitos y disuria. Acude por tal motivo al servicio de urgencias adultos donde a su ingreso el paciente se encontraba con los siguientes signos vitales: presión arterial de 140/90 mm Hg, frecuencia cardiaca de 100 latidos por minuto, frecuencia respiratoria de 20 por minuto y temperatura de $36.6^{\circ} \mathrm{C}$. A la exploración física se encontró paciente masculino de edad aparente a la cronológica, consciente, tranquilo, de buena coloración de piel y tegumentos, adecuado estado de hidratación, neurológicamente íntegro, cabeza y cuello sin datos de importancia, sistema cardiorrespiratorio sin compromiso. Abdomen globoso a expensas de panículo adiposo, dolor en marco cólico y epigastrio, se palpa una masa a nivel de hipogastrio con presencia de dolor intenso a la palpación media y profunda en dicha zona, rebote positivo, peristalsis normal, extremidades sin alteraciones.

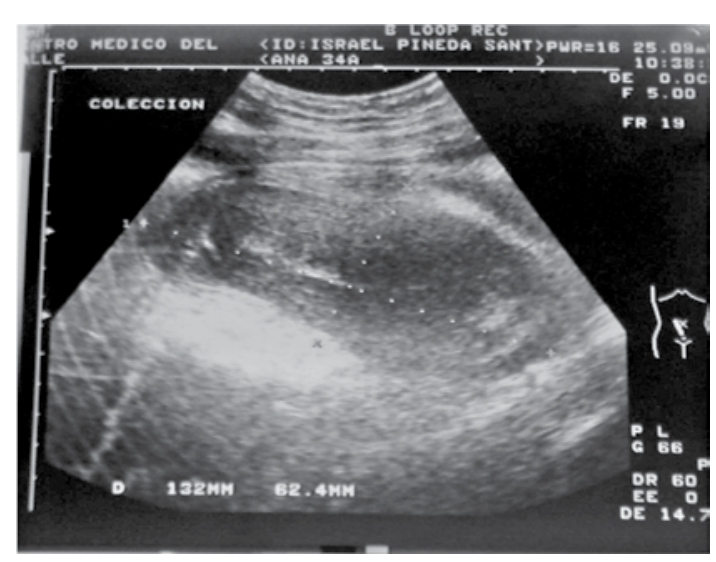

Figura 1.- Se aprecia colección semilíquida de $13 x 6 \mathrm{cms}$ en el hueco pélvico, a considerar absceso (apendicular vs diverticular).

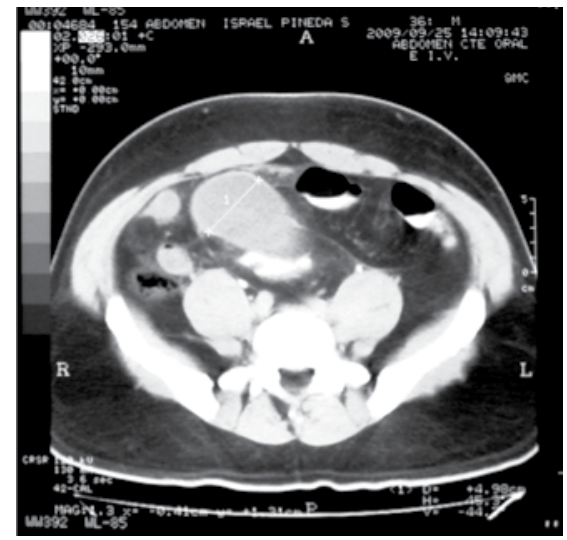

Figura 2.- Imagen en la que se observa el aspecto de una gran colección con un tamaño de $15 \times 6 \mathrm{cms}$.
Exámenes de laboratorio y gabinete de ingreso: hemoglobina 14.9, hematocrito $435 \%$, plaquetas 217000 , leucocitos 8120 , linfocitos $22.6 \%$, neutrófilos totales: $70 \%$, tiempo de protrombina 11.8 , tiempo de tromboplastina parcial: 32.9, INR 1.10, Glucosa 89, Urea 24.7, Creatinina 0.80, $\mathrm{K} 4.00, \mathrm{Na} 139$, transaminasa glutámico oxalacética 121, transaminasa glutámico pirúvica 185, deshidrogenasa láctica 390. Examen general de orina con leucocitos 0-2 por campo, eritrocitos 3-4 por campo, cristales escasos, bacterias moderadas. Se le realiza un ultrasonido abdominal y se decide correlacionar con una tomografía axial computarizada (TAC) de abdomen (figura 1 y 2 ). 
Durante su estancia en el servicio de urgencias adultos, es valorado por especialistas del servicio de Cirugía General, los cuales concluyen que el paciente tiene un diagnóstico de: Colección intrabdominal a descartar enfermedad diverticular, sin embargo refieren que el paciente no cursa con un cuadro clásico de la enfermedad, ni está dentro del grupo etario de mayor afección, ni cuenta con antecedentes de importancia como constipación intestinal, por lo que recomiendan necesario descartar otra etiología de la colección. Encuentran a su revisión al paciente sin datos de abdomen

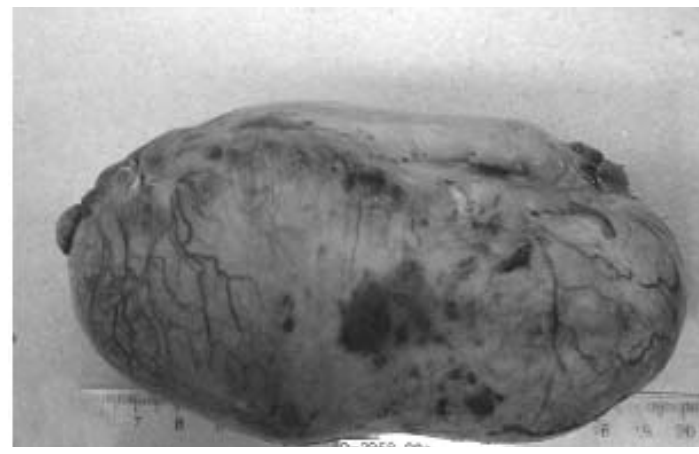

Figura 3.- Macroscopía de apéndice cecal que mide $13.5 \times 6.5 \times 6.5$ centímetros.

La serosa es grisácea-amarillenta con trayectos vasculares evidentes y áreas congestivas. agudo. Consideran entonces necesario de inicio un tratamiento conservador con vigilancia estrecha y antibioticoterapia de amplio espectro. Sugieren realizar drenaje percutáneo guiado por TAC o USG. El paciente nuevamente fue revalorado por el servicio de Cirugía General los cuales consideran necesario efectuar una laparotomía exploradora con los siguientes hallazgos: Apéndice de $12 \times 7 \mathrm{cms}$ compatible con un mucocele apendicular, no perforado. (figura 3 y 4). Se realizó una apendicetomía, el estudio histopatológico reportó: Mucocele apendicular sin atipia. (figura 5).

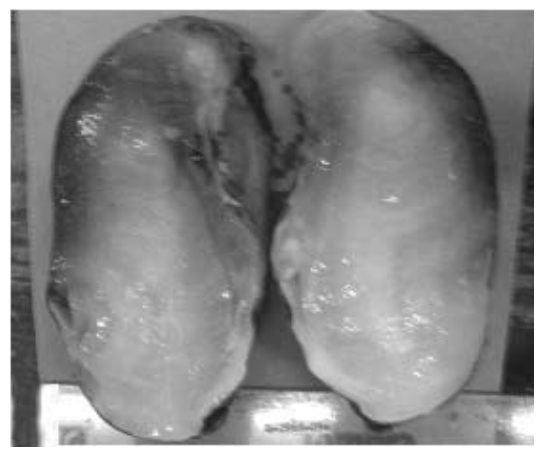

Figura 4.- Al corte se aprecia la pared de $0.1 \mathrm{~cm}$ es bien estratificada. La luz se encuentra ocupada por material mucoide de aspecto gelatinoso.

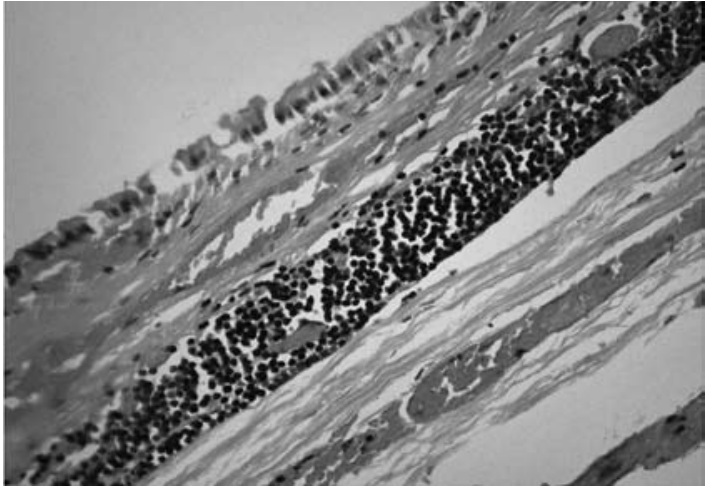

Figura 5: Microscópicamente se observa aplanamiento de la mucosa (atrófica) del apéndice, submucosa con infiltrado inflamatorio de tipo crónico a base de linfocitos con ausencia de folículos linfoides. La capa muscular y serosa adelgazados. 


\section{Discusión}

El apéndice cecal es un órgano de localización retrocecal normalmente, es una evaginación del intestino grueso. Se encuentra revestido por serosa y constituido por capa muscular, submucosa y mucosa. Dentro de las patologías más frecuentes de este órgano se encuentra la apendicitis aguda, infecciones de tipo bacteriano y parasitario, tumores benignos y malignos dentro de los cuales se encuentran el tumor carcinoide que es el más frecuente, cistadenoma mucinoso (mucocele) y cistadenocarcinoma.

El mucocele apendicular es una entidad que se puede presentar con una variedad de manifestaciones clínicas, incluso puede ser un hallazgo accidental en un estudio de imagen por otra causa o en una intervención quirúrgica. ${ }^{11}$

El primer caso fue reportado por Beger en 1882, seguido posteriormente por Rokitansky en 1842, a quien se le atribuye en gran medida el estudio y clasificación de esta patología. Sin embargo, fue hasta 1915 cuando se documentaron los primeros estudios de incidencia como el de Castle, que reportó un $0.2 \%$ de 13,158 autopsias. Posteriormente, Blair (1993) reportó 3 casos en 2,216 apendicectomías. ${ }^{9}$

La presentación clínica del cistoadenoma y del cistoadenocarcinoma es poco específica. En un reciente informe de la Mayo Clinic, Stocchi y cols encontraron en una serie de 135 pacientes, que el 51\% cursaban asintomáticos. Se reportaron como los principales signos y síntomas la presencia de dolor abdominal (27\%), masa abdominal $(16 \%)$ y pérdida de peso $(10 \%) .^{10}$

Dentro de los estudios diagnósticos se encuentran los de laboratorio que son inespecíficos, en mucoceles ocasionados por citoadenocarcinoma pueden identificarse nivel elevados de antígeno carcinoembrionario. ${ }^{8}$ En lo que respecta a estudios de gabinete se recomiendan el enema baritado, la endoscopía y la ecografía; sin embargo, es la tomografía axial de abdomen y pelvis, el estudio que reviste mayor importancia, no sólo por la capacidad de definir claramente la estructura del tumor, sino también en la evaluación de la extensión de la enfermedad a otros órganos. ${ }^{9}$

Es recomendable la realización de una colonoscopía en todo paciente en el que se sospeche la existencia de un mucocele apendicular, para descartar asociación de neoplasia colorrectal. Hay que plantearse el diagnóstico diferencial con neoplasias benignas y malignas de apéndice, región cecal y ovarios (leiomiomas, lipomas, carcinoides o linfomas), así como de otros procesos como endometriosis, piosalpinx, quistes de ovario, mesenquimales, entre otros.

La apendicectomía es la base terapéutica del tratamiento, debido a que, aunque no está demostrado, puede existir la progresión de lesiones benignas a malignas o producirse la rotura del mucocele y desarrollarse un seudomixoma. El procedimiento quirúrgico debe estar en relación con los hallazgos del tumor (extensión, presencia de colección de moco local o difuso por el peritoneo, rotura de apéndice o márgenes de seguridad) y con su histología: se postula la apendicectomía simple en los procesos benignos y la resección cecal o ileocolectomía derecha cuando existe afectación de los segmentos intestinales contiguos, adenopatías regionales, seudomixoma peritoneal o malignidad del proceso. ${ }^{11}$

La apendicectomía en las presentaciones benignas, presentan un excelente pronóstico para el paciente, con sobrevida a 5 años en 91 a 100\% de los casos. Sin embargo, la presencia de células neoplásicas, ya sea por ruptura espontánea o extravasación en el acto quirúrgico, conlleva categóricamente a mal pronóstico, logrando sobrevida a 5 años el $25 \%$, debido a complicaciones del pseudomixoma como la obstrucción intestinal.

En el caso de nuestro paciente se evidencia que, a pesar de contar con datos 
clínicos, de laboratorio así como de gabinete (USG, TAC) no fue posible llegar al diagnóstico, siendo necesario entonces la laparotomía explorada para establecerlo y posteriormente la confirmación mediante el estudio histopatológico.

\section{Conclusiones}

Se concluye que se trata de un tumor poco frecuente de apéndice cecal que clínicamente se puede confundir con un absceso, divertículo o carcinoma primario. Los estudios de laboratorio y de imagen nos orientan al diagnóstico así como al tratamiento, que en este caso y en los casos de revisión de la literatura es quirúrgico el cual tiene buen pronóstico, ya que se trata de un tumor benigno primario de apéndice cecal.

\section{Bibliografía}

1. Minni $F$, Petrella $M$, Morgati $A$, Santini $D$, Marrano $D$, Giant mucocele off the appendix. Report of a case. Dis Colon Rectum 2001;44:1034-1036.

2. Lakatos et al. Mucocele of the appendix: an inusual cause of lowerabdominal pain in a patient with ulcerative colitis. A case report and review of literature. World J Gastroenterol 2005; 11(3): 457-459.

3. Tsutsumi Y, Vergara S, Criales JL. Mucocele apendicular. Hallazgo por ultrasonido. Gac Med Mex 2003;139:169-170.

4. Rosai J. Ackerman's Surgical Pathology. St Louis: Mosby Co, 1996, Eight Edition, Volume one, Chapter: Appendix; 719-20.

5. Utrillas Martínez AC, Muniesa Soriano JA, del Val Gil $J M$, Cruces Conde A, López Peris P, González Penabad M, Sanz Gómez M, Moreno Muzas C. Mucocele apendicular, Rev Esp Enferm Dig (Madrid). 2008;100(11):730-738.

6. De la Fuente Lira $M$, Rocha Guevara ER, Márquez Rocha ML, Salazar Lozano C, Jaramillo Solís O, Ortiz Maldonado AL. Mucocele Apendicular y Colecistitis Aguda Gangrenada, Cirugía y Cirujanos, Academia Mexicana de Cirugía. 2006;74(4):273-277.
7. Butte B, Jean Michel, Torres MJ, Arriagada I, Martínez J. Mucocele Apendicular, Rev. Chilena de Cirugía. 2007;59(2):99-100.

8. Haritopoulos K, Brown D, Lewis P, Manssur F, Eltayar A, Labruzzo $C$ et al: Appendiceal mucocoele; a case report and review of the literature. Int Surg 2001; 86: 259-62.

9. Bahena Aponte Jesús Alberto, Moreno Portillo Mucio, García Arteaga Alinee, "Mucocele Apendicular. Reporte de un caso y revisión de la literatura", Revista Hospital General Dr. "M Gea González" Vol 8, No. 1 Enero-Abril 2007 Págs. 34-36.

10. Stocchi L, Wolff $B$, Larson D. Surgical treatment of appendicecal mucocele. Arch Surg 2003; 138:58589

11. García Lozano A, Vázquez Tarrago A, Castro García C, Richart Aznar J, Segundo Gómez A, Segundo Martínez AM. Mucocele apendicular: presentación de 31 casos Cirugía Española, Servicio de Cirugía General, Hospital Dr. Peset, Valencia, España Publicado por Elsevier España, S.L. 2010;87(2):108 